\title{
MANAGEMENT OF INTRAARTICULAR FRACTURE OF THE BASE OF THE FIRST METACARPAL BONE BY DYNAMIC EXTERNAL FIXATOR
}

\author{
By \\ Mohammed A. M. Abdellah, Mohamed A. Negm and Ahmed Saied \\ Department of Orthopedic Surgery, Faculty of Medicine, Al-Azhar University, Egypt \\ Corresponding author: Mohammed A. M. Abdellah, \\ E-mail: amr.moky.rashwan@ gmail.com
}

\begin{abstract}
Background: Fractures of the hand are common injuries and in particular, fractures involving the articular surfaces can present difficulties to the orthopedic surgeon in practice.

Objective: To assess how to surgically manage intra-articular fracture of the base of the first metacarpal bone by Dynamic K-wire External Fixator.

Subjects and methods: This was a non-randomized clinical trial carried out at Al-Azhar University Hospitals on 10 patients, during the period from March 2018 till May 2020.

Results: The mean time before operation was $9.5 \pm 5$, Blunt trauma was most common type of trauma with a percent of $60 \%$. The mean operative time (minutes) was $40.1 \pm 2$ with range of (30-45) minutes and mean time for $\mathrm{k}$ wire removal was $28.1 \pm 5$ with range of (15-41). There was significant improvement of Quick DASH functional scoring. There was high significant improvement of range of motion. There is significant difference between the normal and operated side as regard range of motion. Regarding complications, $10 \%$ of cases had post-operative pain which continued whole period of follow up, $0 \%$ had secondary arthrosis, $10 \%$ had superficial pin tract infection and $0 \%$ had valgus deformity.

Conclusion: Closed reduction and external fixation can be effective and safe treatments for unstable fractures at the base of the first metacarpal. Such external fixation structures were simple and versatile and able to simultaneously achieve effects such as meeting the retractor, adjusting the angulation, and shortening the displacement, especially for local wounds.
\end{abstract}

Keywords: Rolando fracture, Thumb, Metacarpal, External fixator.

\section{INTRODUCTION}

Fractures of the base of the first metacarpal are classified into intra- and extra-articular fractures. The intraarticular fractures can be subdivided into Bennett and Rolando fractures (Kong et al., 2013). Intra-articular fracture of base of the first metacarpal fractures makes up to $1.4 \%$ of all fractures of the hand (Marsland et al., 2012).

Rolando fracture refers to a specific tripartite fracture of the base of the thumb metacarpal. Classically, the Y- or Tshaped fracture line runs longitudinally through the metaphyseal area, with an intra-articular fracture splitting the metacarpal base fragment into a volar and a dorsal fragment. The Y-shaped type 
describes any comminuted intra-articular fracture of the base of the first metacarpal (El-Sharkawy et al., 2012).

A Bennett fracture is further classified into three types. Type 1 represents fractures with a large ulnar fragment and subluxation of the metacarpal base, type 2 are impaction fractures without subluxation, and type 3 are metacarpal dislocations with a small ulnar avulsion fragment (Oak and Lawton, 2013).

Percutaneous pinning can join adjacent fragments and/or metacarpals, and/or the first metacarpal and the trapezium bone and open reduction, and internal fixation can be carried out by dorsal or volar approach using pins, screws, or tension bands as osteosynthesis (Zhang et al., 2017).

The treatment of intra-articular fractures to the bases of the metacarpals varies from closed reduction and casting to open reduction and internal fixation (ORIF). There is no consensus for optimal treatment, because these injuries occur infrequently (Oak and Lawton, 2013).

Many types of external fixation were used to lessen the intra-articular fractures by ligamintotaxis and early mobilization as force couple splint (Abou Elatta et al., 2017), rubber and pin system, (Kamath et al., 2011), Y18 BS [Quattero, compass device (Magnotti et al., 2018), dynamic traction method of Schenck (Elfar and Mann, 2013), modified rubber and pin system (Waljee et al., 2011), spring device (Khouri et al., 2013), and the dynamic devices that were suggested by Badia and his colleagues and hyens and giddins, suggested Asal modified Suzuki system for treatment of proximal interphalangeal joint fractures by using the cerclage wire instead of rubber and made rings at the end of the K-wires (F. Asal, personal communication) (Park et al., 2019).

In our study, we were assessing how to surgically manage intra-articular fracture of the base of the first metacarpal bone by Dynamic K-wire External Fixator.

\section{PATIENTS AND METHODS}

The current study was carried out at the outpatient of Al-Azhar University Hospitals during the period from March 2018 till May 2020. This was a prospective observational study to follow patients with the intra-articular fractures of the base first metacarpal bone who was identified, 10 patients were recruited and patient characteristics, comorbidities, interventions, and complications were recorded.

The ethics committee of the University confirmed the study methodology. Informed consent was taken from all patients included in the study.

All subjects gave a complete full history taking which as include demographic features (age, gender and occupation, where it was categorized into 'heavy manual', 'light manual' and 'office work'), clinical variables (cause of fracture which was categorized into low energy falls, a fight and a fall from a height, site of fracture, its type and severity and the mean time to surgery from the date of injury) was documented. The mean time to removal of the external fixator was 28 days (range: 15-41 days, median: 27 days).

The surgery was performed with the patient positioned supine and the forearm was held in midprone position a high-arm 
tourniquet applied. A broad spectrum antibiotic was administered intravenously for bacterial prophylaxis on induction of anesthesia, followed by routine skin preparation and draping of the arm.

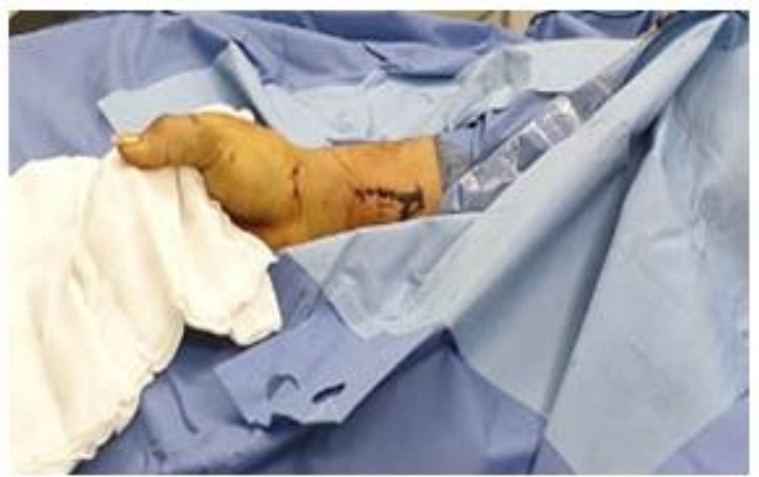

Figure (1): The patient positioned supine and the forearm was healed in the mid prone position on side arm table

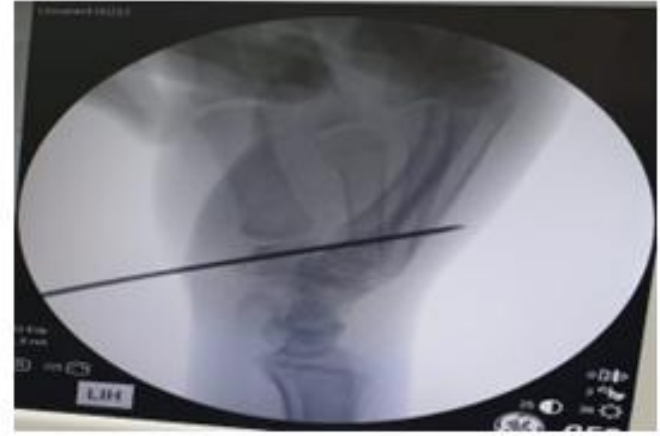

(A)

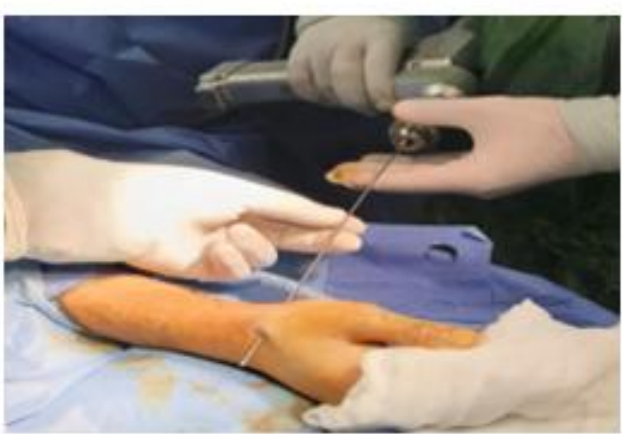

(B)

Figure (2): (A) k-wire was inserted transversely through the trapezium, (B) C-arm photo of first k-wire through the trapezium

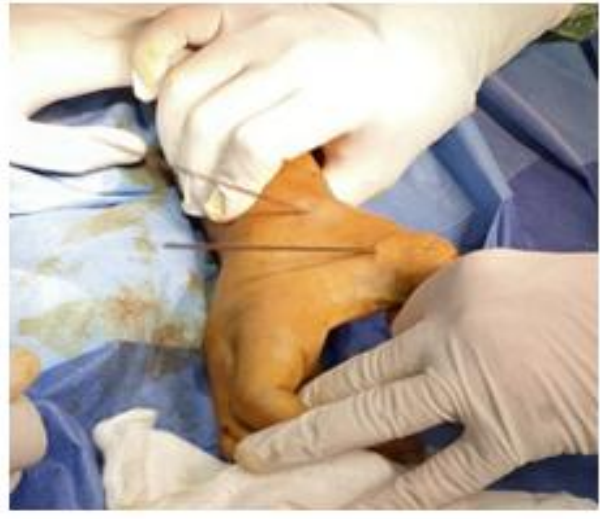

(A)

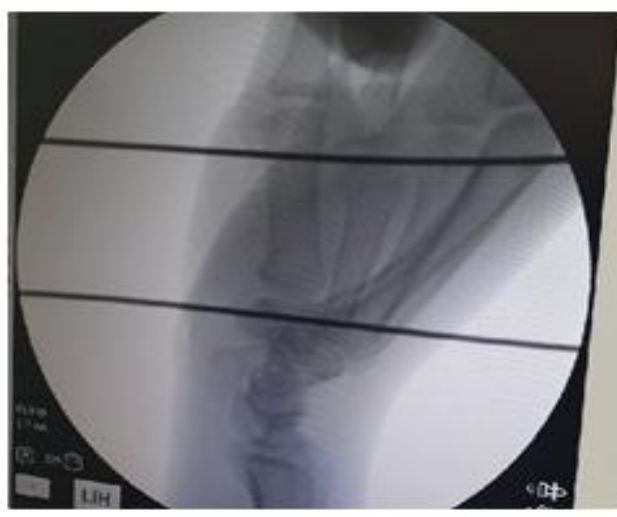

(B)

Figure (3): (A) Another k-wire was inserted through the first metacarpal Proximal to the metacarpo phalangeal joint (traction pin), (B) $\mathrm{C}$-arm photo showing another $\mathrm{k}$ wire inserted in the first Metacarpal bone proximal to metacarpo phalangeal joint 


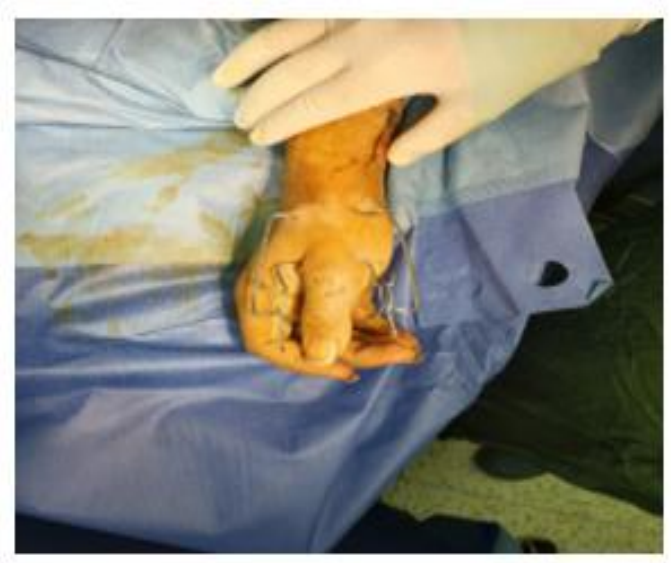

(A)

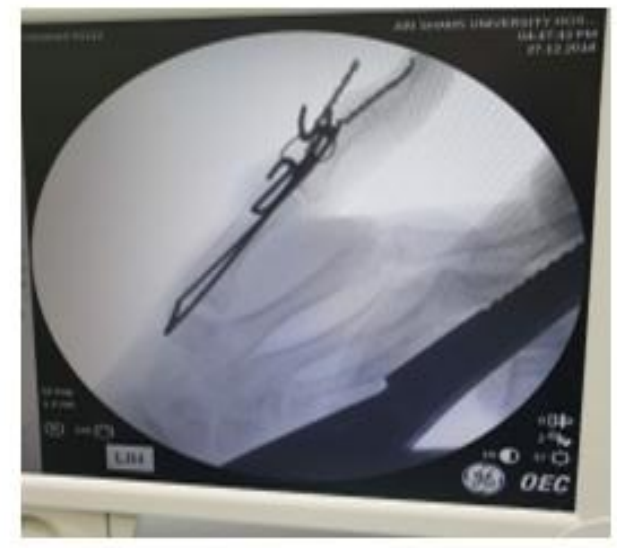

(B)

Figure (4): (A) The ends were reshaped into small circles just away from the Skin, (B) C-arm photo showing the reshaped ends of wires

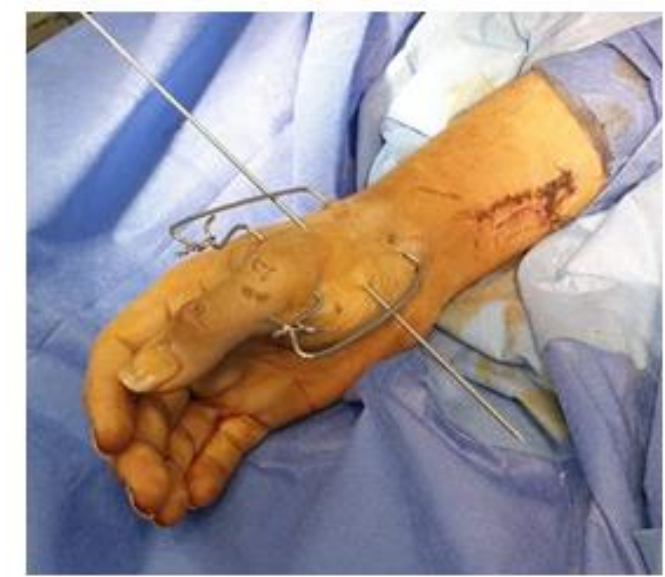

(A)

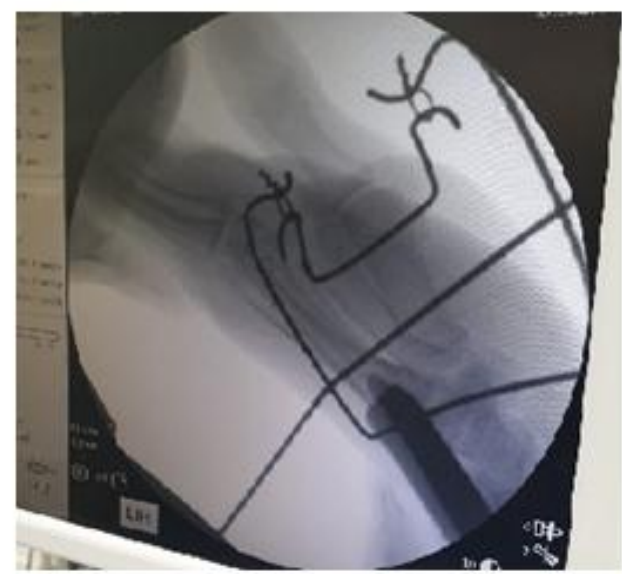

(B)

Figure (5): (A) A k-wire was inserted in the first metacarpal just above the fracture site parallel to the previous 2 wires. The wire was bent 90 degrees distally on both sides (reduction pin), (B) C-arm photo 


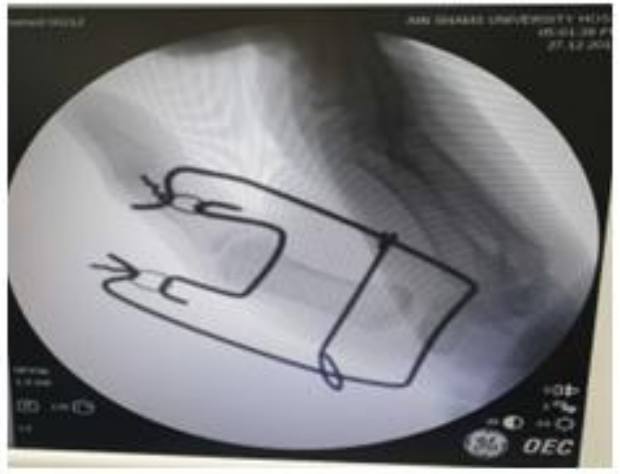

(A)

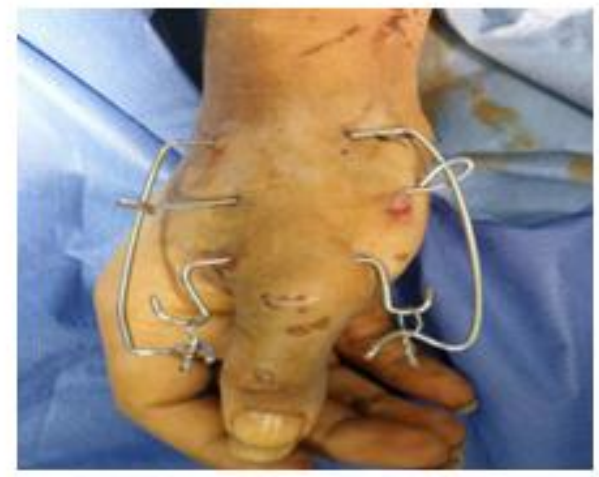

(B)

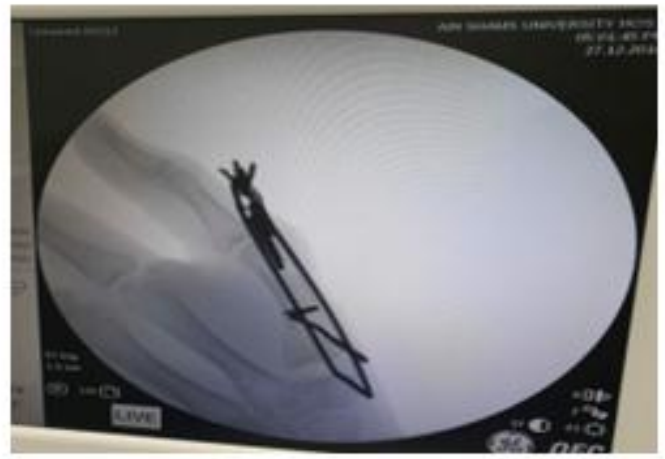

(C)

Figure (6): (A) Another 2 circles at the ends of the wire were made just distal to the most distal k-wire. After the wires touch the proximal wire they were angulated dorsally. The cicles of both ends of both proximal and distal wires were held together with cerclage wires made into loops and then the traction was increased gradually until the reduction was achieved. The reduction pin was bent in both sides 90 degrees dorsally to prevent the slippage of wire, (B) $\mathrm{C}$-arm photo $\mathrm{AP}$ view, (C) $\mathrm{C}$-arm photo

\section{LT view}

A mini $\mathrm{C}$-arm image intensifier was used to ensure accurate fracture reduction. Patients were encouraged to mobilize the hand and wrist as pain allowed. It was planned to remove the external fixator at four weeks, at which point active and passive thumb exercises were commenced.

Follow-up after surgery was assessed on a symptomatic and radiological basis on $1^{\text {st }}, 2^{\text {nd }}, 3^{\text {rd }}$ and $4^{\text {th }}$ week. To evaluate the outcome of surgical management of the intraarticular fracture of the base of the first metacarpal bone regaining the active range of motion of all thumb joints including the carpometacarpal joint following surgery, the ability to prevent joint ligament and periarticular contractures and post-operative complications (pain, late secondary arthrosis and infection).

Inclusion criteria: Age range between 15-75 years with intra-articular fracture of the base of the first metacarpal bone. 
Exclusion criteria: Patients below 15 years and above 75 years, Patient with stable fractures and Patients with co morbidities that interfere with anesthetic condition.

Statistical Analysis: Data will be collected, summarized and reported on data collection sheets. Data is to be reentered into computer Microsoft Excel sheets with appropriate tabulation and graphical presentation by SPSS version 20. All data will then be analyzed using: Chi square is to be used to compare different frequencies.

- Description of quantitative variables in the form of mean and standard variation.
- Description of qualitative variables in the form of frequency and percentages.

- T-student test of independent samples used to compare each two quantitative groups.

- Comparison between two related sample for non-parametric data using Wilcoxon Rank Sum test.

- Correlation Co-efficient test (r-test) was used to rank the different variables against each other either directly or indirectly.

- $\mathrm{X} 2$ = Chi - square test used to compare quantitative variables.

Pvalue $<0.05 \mathrm{w}$ as Considered Significant

\section{RESULTS}

Mean time before operation was $9.5 \pm 5$; Blunt trauma was most common type of trauma with a percent of $60 \%$. The mean operative time (minutes) was $40.1 \pm 2$ with range of (30-45) minutes and mean time for $\mathrm{k}$ wire removal was $28.1 \pm 5$ with range of (15-41) (Table 1).

Table (1): Characteristic of injury among the studied cases

\begin{tabular}{|c|c|c|}
\hline Variable & \multicolumn{2}{|c|}{$(n=10)$} \\
\hline $\begin{array}{l}\text { The mean time before operation(days): } \\
\text { Mean } \pm \text { SD } \\
\text { Range }\end{array}$ & \multicolumn{2}{|c|}{$\begin{array}{c}9.5 \pm 5 \\
(1-18)\end{array}$} \\
\hline & No. & $\%$ \\
\hline $\begin{array}{l}\text { Type of trauma: } \\
\text { Road traffic accidents } \\
\text { Blunt trauma } \\
\text { Sharp injury }\end{array}$ & $\begin{array}{l}3 \\
6 \\
1\end{array}$ & $\begin{array}{l}30.0 \\
60.0 \\
10.0\end{array}$ \\
\hline $\begin{array}{l}\text { The mean operative time (minutes): } \\
\text { Mean } \pm \text { SD } \\
\text { Range }\end{array}$ & \multicolumn{2}{|c|}{$\begin{array}{l}40.1 \pm 2 \\
(30-45)\end{array}$} \\
\hline $\begin{array}{l}\text { The mean time for } k \text { wire removal (days): } \\
\text { Mean } \pm \text { SD } \\
\text { Range }\end{array}$ & \multicolumn{2}{|c|}{$\begin{array}{l}28.1 \pm 5 \\
(15-41)\end{array}$} \\
\hline
\end{tabular}


The patients Quick DASH in cases with pre-operative median (IQR) 9 (2) compared to postoperative median (IQR) 4 (3), with p-value <0.001 highly significant improvement post-operative compared preoperative according to Quick DASH functional scoring (Table 2).

Table (2): Comparing the pre and post-operative QuickDASH functional scoring

\begin{tabular}{|c|c|c|c|c|}
\hline Variable & Pre -operative $(\mathrm{n}=10)$ & Post-operative $(\mathrm{n}=10)$ & P value \\
\hline \multicolumn{5}{|c|}{ QuickDASH functional scoring } \\
\hline Median (IQR)
\end{tabular}

IQR: Interquartile range

Using: Wilcoxon test; p-value <0.001 HS

$100 \%$ of cases had normal union on $\mathrm{x}$ ray shows that $10 \%$ of cases had postoperative pain which continued whole period of follow up, $0 \%$ had secondary arthrosis, $10 \%$ had superficial pin tract infection and $0 \%$ had valgus deformity (Table 3).

Table (3): Post-operative radiological findings and complications of the studied cases.

\begin{tabular}{|l|c|c|}
\hline \multicolumn{1}{|c|}{ Variable } & \multicolumn{2}{c|}{ (n=10) } \\
\hline Radiological findings & No. & \% \\
\hline Union & 10 & 100.0 \\
Non union & 0 & 0.0 \\
Malunion & 0 & 0.0 \\
\hline Complications & No. & $\%$ \\
\hline pain & 1 & 10.0 \\
secondary arthrosis & 0 & 0.0 \\
superficial pin tract infection & 1 & 10.0 \\
valgus deformity & 0 & 0.0 \\
\hline
\end{tabular}

\section{Case data:}

\section{A. Personal history:}

- Name: Ala.

- Age at surgery: 19.

- Sex: male.

- Hand dominance: right.

- Affected side: right.

- Time since injury: One day.

- Occupation: Door-man.

- Mode of trauma: Blunt trauma.

- Associated injury: No associated injury.

- Follow up period: Six weeks.

B. Pre-operative evaluation: Confirm fracture of base of first metacarpal using X-ray (Fig. 8). 

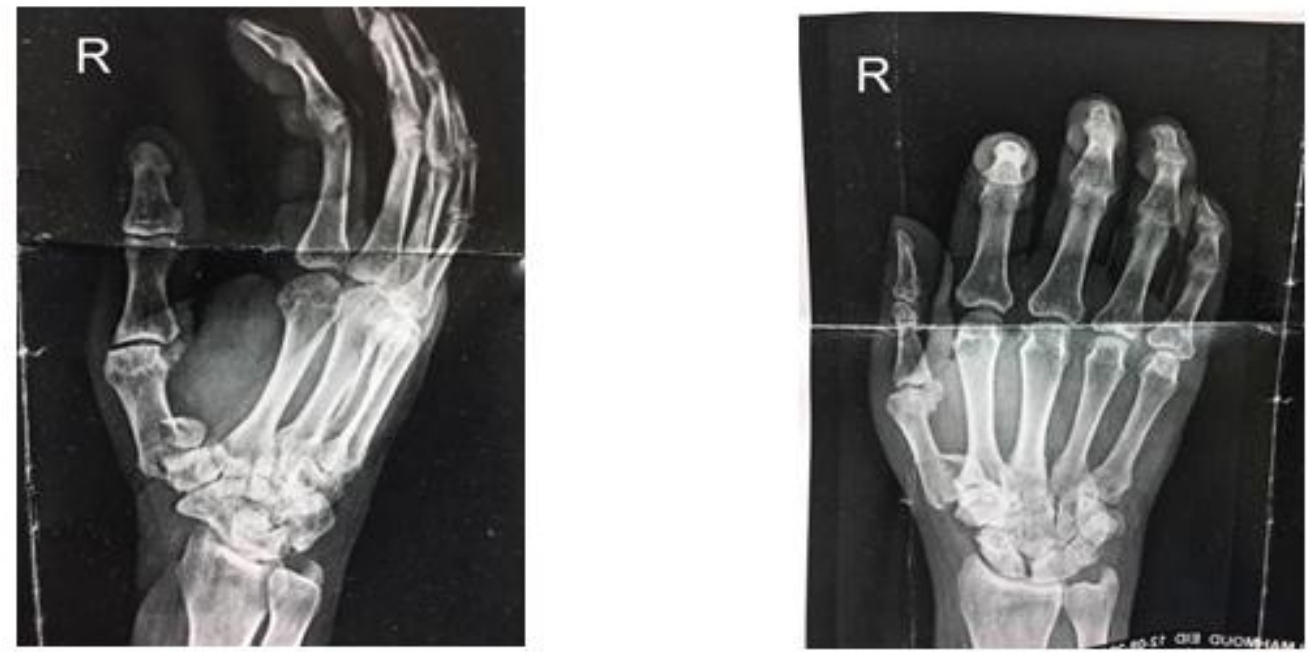

Figure (8): X-ray of a case of Rolando fracture

C. Intra-operative data: Fixing the fracture of base of first metacarpal using K-wires as a dynamic external fixator (Fig. 9).
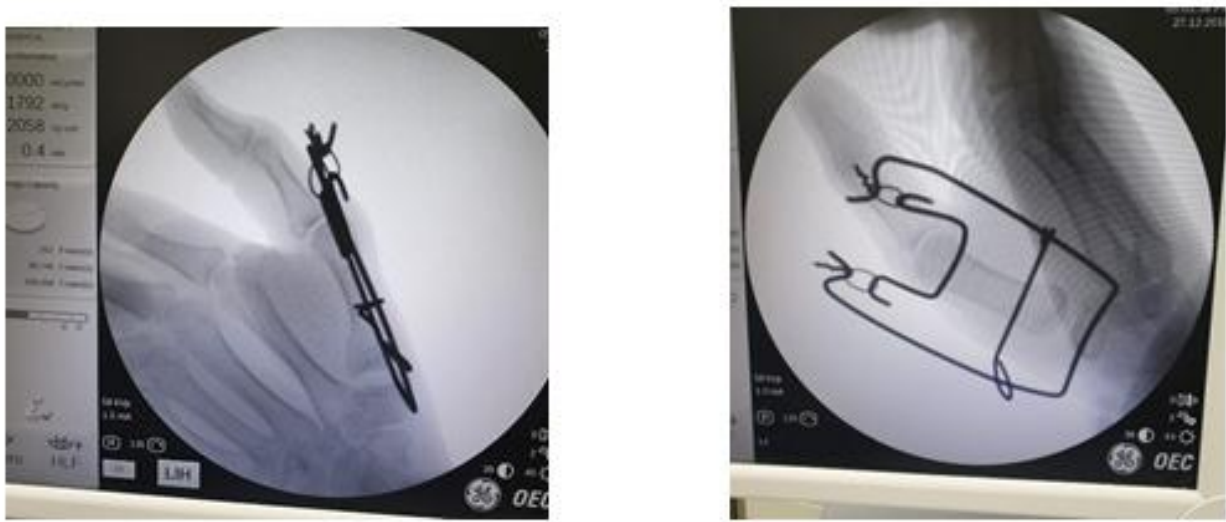

Figure (9): Intra operative $\mathrm{C}$-arm photo shows the frame and the reduction

Complete union of the fracture of the base of first metacarpal bone (Fig. 10).
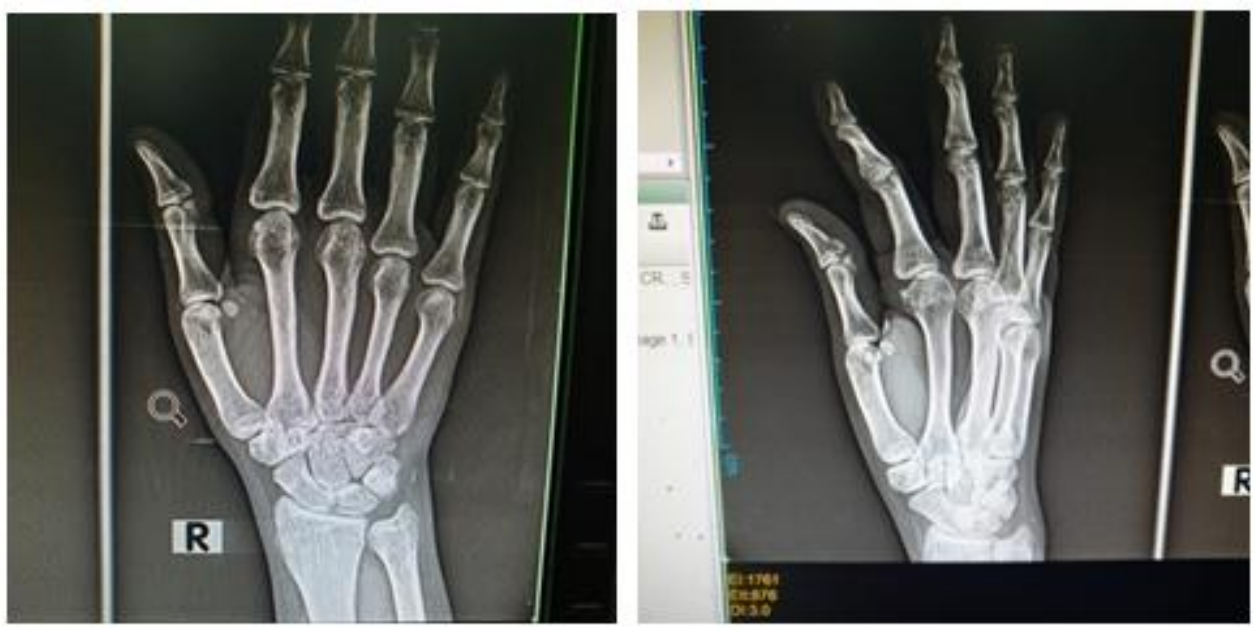

Figure (10): Union three months after operation of the previous case 
D. Post-operative: Regaining the active range of motion of all thumb joints including the carp-metacarpal joint following surgery, no post-operative complications pain, infection and late arthrosis, no ligament and peri-articular contracture (Fig. 11).
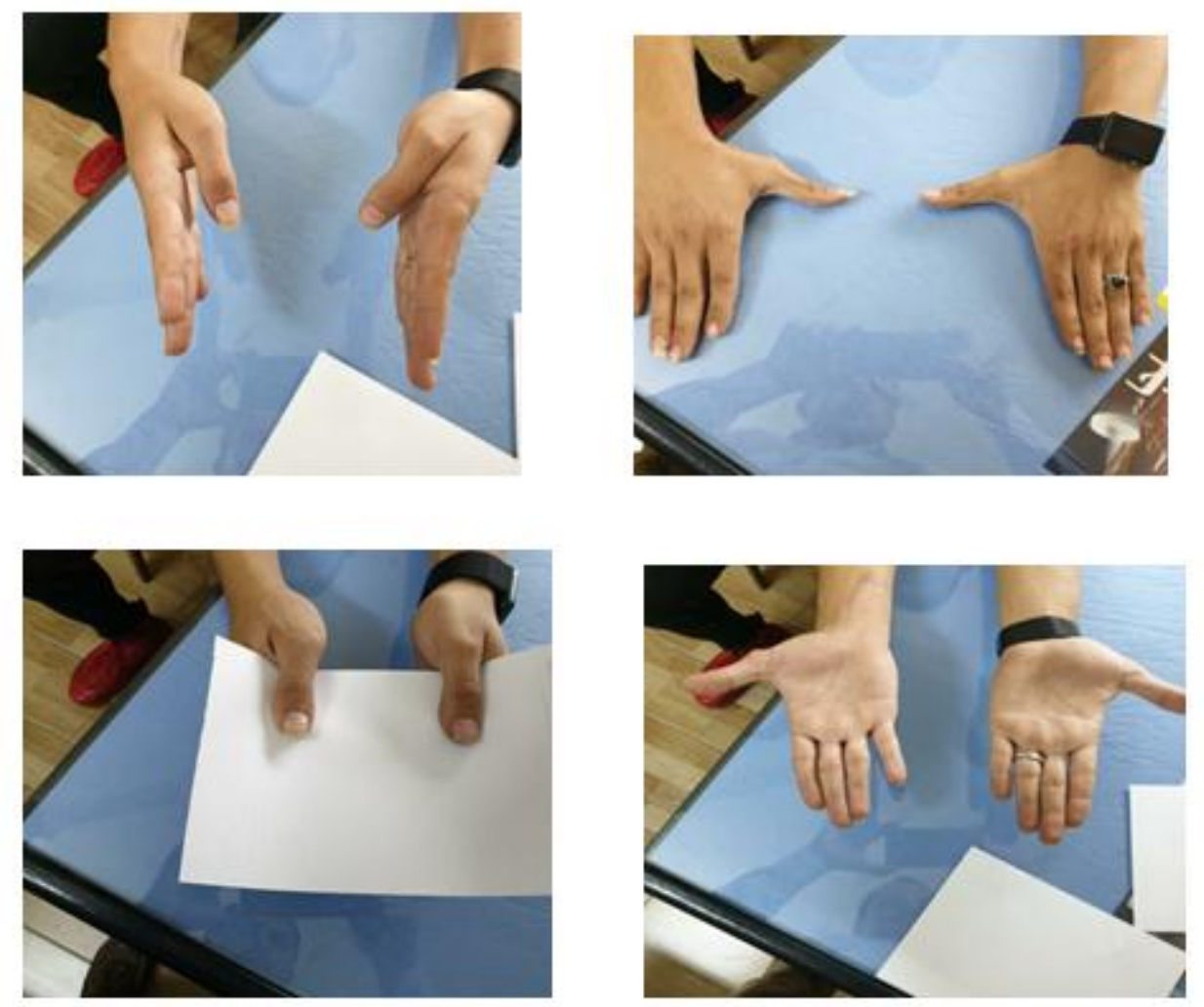

Figure (11): Range of motion

\section{DISCUSSION}

In the present study, the mean time before operation was $9.5 \pm 5$, Blunt trauma was most common type of trauma with a percent of $60 \%$. The mean operative time (minutes) was $40.1 \pm 2$ with a range of 30 45 minutes and mean time for $\mathrm{k}$ wire removal was $28.1 \pm 5$ with range of $15-41$. This was are in agreement with study of Zhang et al. (2017) as they reported that the mean intra operative time was 43.85 minutes (range, 20-62 minutes).

Diaz-Garcia and Waljee (2013) reported that the mean time of delay since injury until the operation was 9.5days (range, 1 Y18 days). The mean time of the device's removal was 38.5 days (range,
34 Y45 days). The mean follow-up was 6.5months (range, 3Y10 months). The mean operative time was 40minutes (range, 30Y45 minutes).

Regarding Greeven et al. (2012) the average operation time was $27 \mathrm{~min}$ (range 5-190 $\mathrm{min}$ ). None of the fracture showed dislocation at a 1-monthfollow-up. Kwires were removed after a mean of 32 days (range28-50 days).

According to Salunkhe et al. (2016), the average duration of surgery was 45 min. Average blood loss was $5 \mathrm{ml}$. The average stay in the hospital was 1 day. Most of the patients were involved in industrial trauma and road traffic accident. 
Our results showed that there was significant improvement of Quick DASH functional scoring.

Zhang et al. (2017) reported that Joint function was assessed according to the disability of the arm; shoulder and hand (DASH) scale of 0-100 points in which a higher score indicated a greater loss of functionality. The pinch strength of the affected side for one case with type I fractures was a26.7\% loss compared with that of the uninjured side without functional limitations and DASH score was 3 points. Middleton et al. (2015) observed that after a mean of 41 (SD, 24) months of treatment, the mean DASH score was 3.4 (SD, 5.4). Farag and Essawy (2015) reported that average QuickDash score was $6( \pm 3.5)$ ranging from zero to13.5 points.

The present study showed that there was a significant improvement of range of motion. There is significant difference between the normal and operated side as regard range of motion.

Diaz-Garcia and Waljee (2013) observed that the mean range of motion of the interphalangeal joints was $100 \%$, as the healthy one, whereas the metacarpophalangeal joints were $98.75 \%$. The mean radial thumb abduction was $95 \%$, and the palmar thumb abduction was $95.5 \%$, whereas the thumb pronation was $92.25 \%$. The mean power grip of the affected side was $96.25 \%$ of the healthy one. All joints spaces were restored.

In our study, regarding radiological findings, $100 \%$ of cases had normal union on $\mathrm{x}$ ray.Our results were supported by study of Zhang et al. (2017).
The present study showed that, $10 \%$ of cases had post-operative pain which continued whole period of follow up, no secondary arthrosis, $10 \%$ had superficial pin tract infection and no valgus deformity. Our results were supported by study of Diaz-Garcia and Waljee (2013). Farag and Essawy (2015) found that the mean visual analogue score for pain was $1.5( \pm 0.9)$ ranging from zero to 4 .

The present study showed that there was no statistically significant correlation between the post-operative Quick DASH functional scoring and age or the duration before the operation.

Zhang et al. (2017) reported that age was an important prognostic factor, and elderly patients were more likely to have postoperative partial pain and decreased muscle strength and were more prone to joint degeneration in the advanced disease stage.

The limitations of the present study were that nearly $20 \%$ of patients did not complete the 24-months follow-up period. In addition, objective assessment criteria were lacking. During the Jamar dynamometer strength test, the dominant hand was not considered and some errors occurred.

In our opinion, our K-wire constructed offers an excellent solution for a comminuted fracture of the base of the first metacarpal.

\section{The advantages are as follows:}

1. Simplicity and easy insertion.

2. Inexpensiveness.

3. Ability to decrease the operative time.

4. Readjust ability in the outpatient clinic. 
5. Having no dissection or devascularization of soft tissue and bone.

6. Having early active range of motion of all thumb joints including the carpometacarpal joint.

7. Ability to reduce fracture fragments and realign joint surfaces by ligamentotaxis.

8. Ability to prevent joint ligament and periarticular contractures.

9. Ability to prevent fracture fragment collapse.

10. Ability to avoid more extensive surgery.

11. having early and continuous motion in synovial joints that enhances the nutrient and metabolic activity of the articular cartilage, stimulating pluripotential mesynchymal cells to differentiate from articular cartilage, as opposed to either fibrous tissue or bone, thereby leading to healing and regeneration of the cartilage and accelerating healing of articular cartilage and periarticular tissues such as tendons and ligaments.

\section{Disadvantages:}

It is bulky, maybe caught on the patient's clothes, and may result in interact infection.

\section{CONCLUSION}

Closed reduction and external fixation can be effective and safe treatments for unstable fractures at the base of the first metacarpal. Such external fixation structures are simple and versatile and able to simultaneously achieve effects such as meeting the retractor, adjusting the angulation, and shortening the displacement, especially for local wounds.

\section{REFERENCES}

1. AbouElatta MM, Assal F, Basheer HM, El Morshidy AF, Elglaind SM and Abdalla, MA. (2017): The use of dynamic external fixation in the treatment of dorsal fracture subluxations and pilon fractures of finger proximal interphalangeal joints. Journal of Hand Surgery, 42(2): 182-187.

2. Diaz-Garcia R, and Waljee JF. (2013): Current management of metacarpal fractures. Hand Clinics, 29(4): 507-518.

3. Elfar J and Mann T. (2013): Fracturedislocations of the proximal interphalangeal joint. The Journal of the American Academy of Orthopaedic Surgeons, 21(2): 88.

4. Farag $H$ and Essawy O. (2015): Fifth metacarpal fractures; Treatment by low-cost syringe fixator. Al-AzharAssiut Medical Journal, 13(2): 118-122.

5. Greeven APA, Alta TDW, Scholtens REM, de Heer $P$ and van der Linden FM. (2012): Closed reduction intermetacarpalKirschner wire fixation in the treatment of unstable fractures of the base of the first metacarpal. Injury, 43(2): 246-251.

6. Kamath JB, Naik DM and Bansal A. (2011): Current concepts in managing fractures of metacarpal and phalangess. Indian Journal of Plastic Surgery, 44(02): 203-211.

7. Khouri JS, Bloom JM and Hammert WC. (2013): Current trends in the management of proximal interphalangeal joint injuries of the hand. Plastic and Reconstructive Surgery, 132(5): 1192-1204.

8. Kong H, Yueh JH and Granick M. (2013): Fracture of the Base of the First Metacarpal Bone. Eplasty, 13: 7-12.

9. Magnotti C, Figueroa E, Farias JG, Merino O, Valdebenito I, Oliveira RPS and Cerqueira V. (2018): Sperm characteristics of wild and captive lebranche mullet Mugilliza (Valenciennes, 1836): subjected to sperm activation in different $\mathrm{pH}$ 
and salinity conditions. Animal Reproduction Science, 192: 164-170.

10. Marsland D, Sanghrajka A and Goldie B. (2012): Static monolateral external fixation for the Rolando fracture: a simple solution for a complex fracture. Annals of the Royal College of Surgeons of England, 94(2): 112115.

11. Oak $N$ and Lawton JN. (2013): IntraArticular fractures of the hand. Hand Clin., 29: 535-549.

12. Park JH, Park GW, Choi IC, Kwon YW and Park JW. (2019): Dorsal transosseous reduction and locking plate fixation for articular depressed middle phalangeal base fracture. Archives of Orthopaedic and Trauma Surgery, 139(1): 141-145..
13. Salunkhe RM, Joshi H, Pisal TK, Biswas SK, Patel JJ and Singh A. (2016): A prospective study of dynamic treatment of fracture phalanx and metacarpals of the hand with Kirschner-wire fixation/external fixator and finger splint: Daycare management (30 cases). Medical Journal of Dr. DY Patil University, 9(6): 708.

14. Waljee JF, Kim HM, Burns PB and Chung KC. (2011): Development of a brief, 12-item version of the Michigan Hand Questionnaire. Plastic and Reconstructive Surgery, 128(1): 208-212.

15. Zhang Y, Xu N, Gu W and Jiang S. (2017): Two-year follow-up of closed reduction and external fixation treatment of unstable fractures at the base of the first metacarpal. Biomedical Research, 28 (3): 1396-1402. 


\section{مناجزة الكسر داخل المفصل من قاعدة العظم السنعي الاول

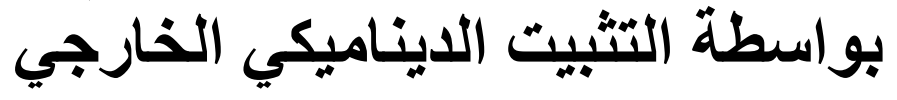 \\ محمد أحمد ماهر، محمد عبد المنعم نجم، أحمد سعيد}

قسم جراحة العظام، كلية الطب، جامعة الأزهر

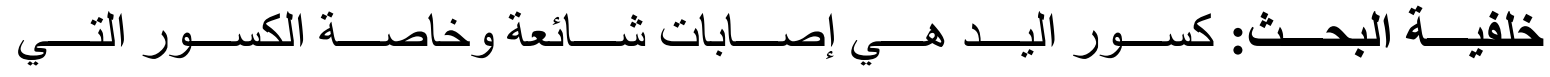

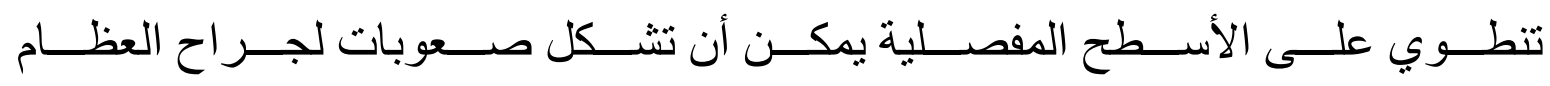
في الممارسة.

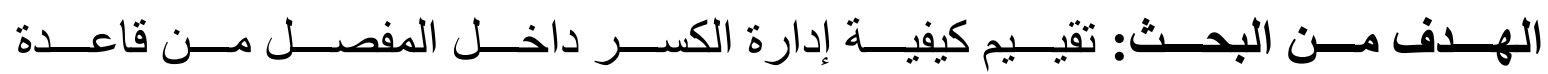
العظم السنعى الاول بو اسطة التثبيت الديناميكى الخارجى جر احيا.

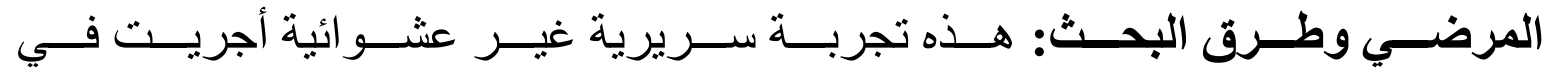

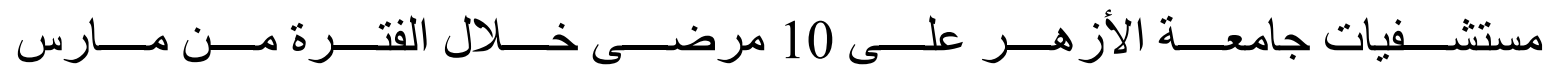
2018 حتى مارس 2020.

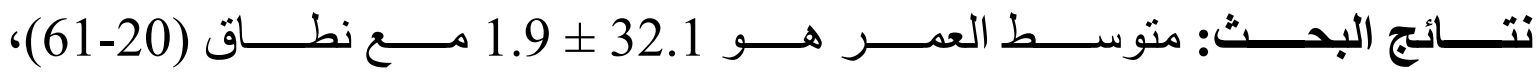

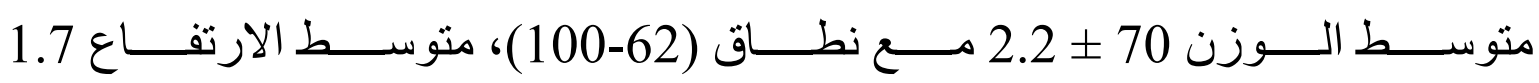

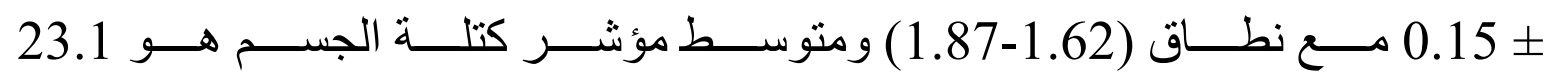

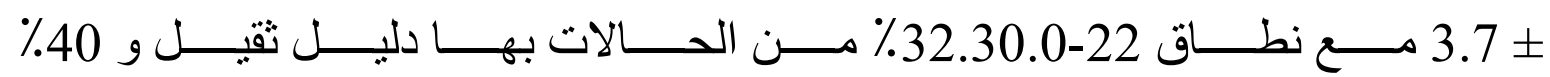

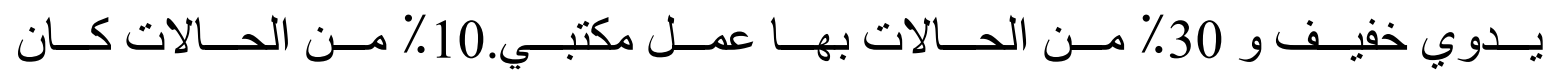

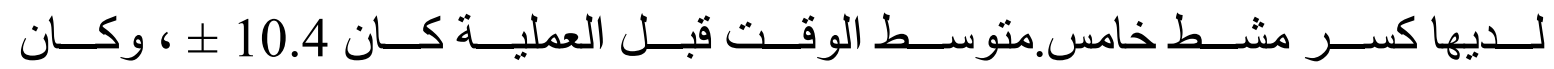

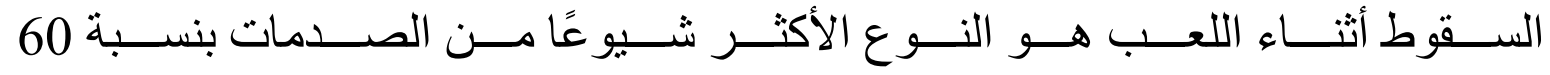

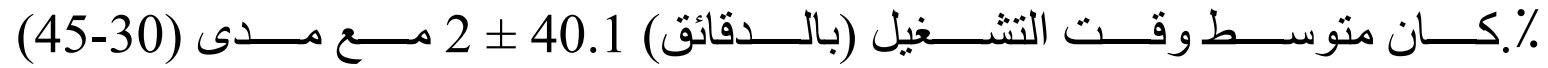

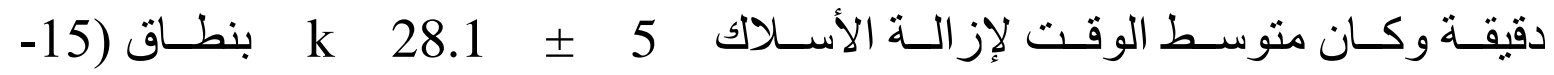

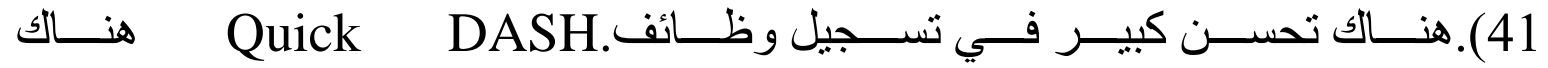

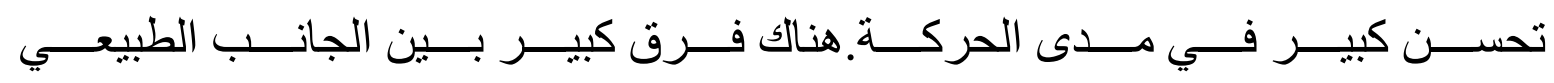




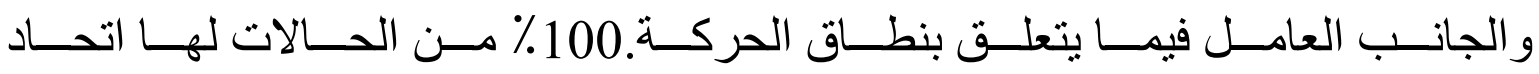

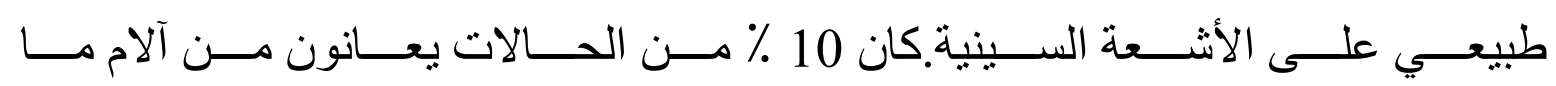

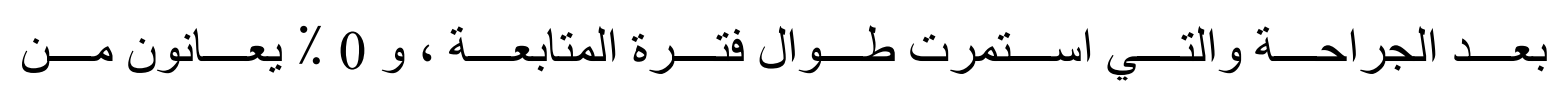

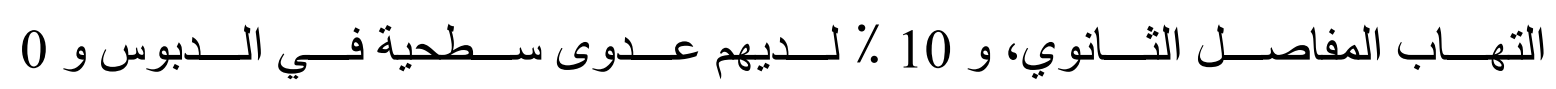

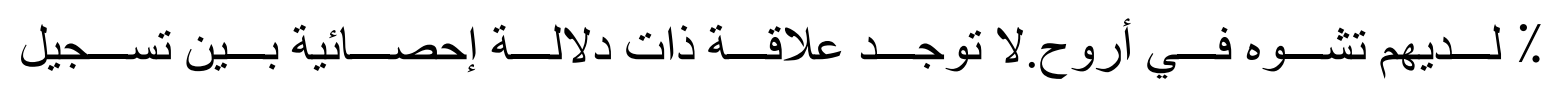
وظيفة Quick DASH بعد العملية والعمر أو المدة قبل العملية.

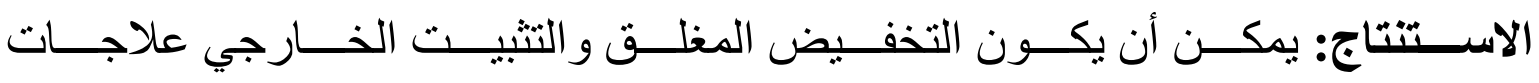

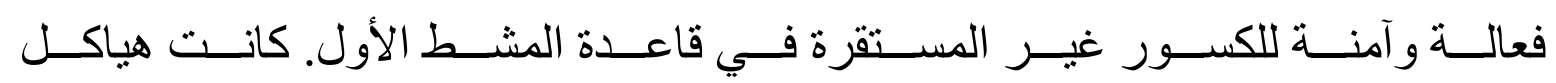

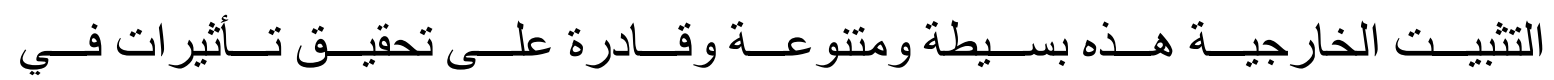

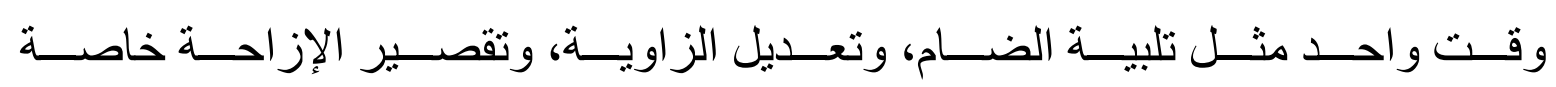
بالنسبة للجروح المحلية. 